\title{
Expression of seed storage product genes (CRA1 and OLEO4) in embryogenic cultures of somatic tissues of Arabidopsis
}

\author{
Marta Gliwicka $\cdot$ Katarzyna Nowak • \\ Edyta Cieśla $\cdot$ Malgorzata D. Gaj
}

Received: 26 July 2011/Accepted: 19 November 2011/Published online: 6 December 2011

(C) The Author(s) 2011. This article is published with open access at Springerlink.com

\begin{abstract}
In Arabidopsis, immature zygotic embryos (IZEs) at the late cotyledon stage provide the only explants that can be used to induce in vitro somatic embryogenesis (SE) with high efficiency. The most conspicuous characteristic of SE-competent IZEs is the accumulation of seed storage reserves (SSR), as proteins and lipids. In order to elucidate an assumed role of these compounds in the mechanisms involved in tissue capacity for SE, the genes encoding the main seed storage protein, cruciferin ( $C R U$ CIFERINI, CRA1) and the lipid body-related protein oleosin (OLEOSIN4, OLEO4), were studied. Significantly higher transcriptional activity of both genes, CRAl and OLEO4, in embryogenic than in non-embryogenic cultures, were indicated. However, their activity under in vitro culture were found not to be induced by auxin treatment or $L E C 2$ expression, and were unspecific for SE induction. In addition, the results on mutants severely impaired in SE response indicated that high activity of SSR genes in explant tissue is not sufficient for SE induction. On the other hand, the cral and oleo 4 insertional mutants were found to be defective in their capacity for SE. In addition, it was found that the mutants displayed lower tolerance to high salinity and osmotic stress. Altogether, the results suggest an indirect influence of $S S R$ genes on the embryogenic capacity of cultured tissues possibly via improvement of cell response to stress imposed in vitro.
\end{abstract}

Electronic supplementary material The online version of this article (doi:10.1007/s11240-011-0089-2) contains supplementary material, which is available to authorized users.

M. Gliwicka · K. Nowak · E. Cieśla · M. D. Gaj ( $₫)$

Department of Genetics, University of Silesia,

ul. Jagiellonska 28, 40-032 Katowice, Poland

e-mail: mmdgaj@us.edu.pl
Keywords CRUCIFERIN1 - Immature zygotic embryos · LEC2 overexpression - OLEOSIN4 - Real-time qPCR . Shoot organogenesis - Somatic embryogenesis .

SE-impaired mutants

$\begin{array}{ll}\text { Abbreviations } \\ \text { 2,4-D } & 2,4-\text { Dichlorophenoxyacetic acid } \\ \text { 2iP } & 6 \text {-( } \alpha, \alpha \text {-Dimethylallylamino)-purine } \\ \text { BAP } & \text { Benzyl adenine } \\ \text { CIM } & \text { Callus induction medium } \\ \text { IAA } & \text { Indole-3-acetic acid } \\ \text { IZE } & \text { Immature zygotic embryo } \\ \text { MZE } & \text { Mature zygotic embryo } \\ \text { NAA } & \text { Naphthalene acetic acid } \\ \text { ORG } & \text { Organogenesis } \\ \text { PSV } & \text { Protein storage vacuoles } \\ \text { SE } & \text { Somatic embryogenesis } \\ \text { SIM } & \text { Shoot induction medium } \\ \text { SSP } & \text { Seed storage protein } \\ \text { SSR } & \text { Seed storage reserves } \\ \text { TAG } & \text { Triacylglycerols } \\ \text { ZE } & \text { Zygotic embryogenesis }\end{array}$

\section{Introduction}

Since not all somatic cells have capacity for totipotency, and therefore in order to regenerate plants in vitro, it is challenging to identify the internal and external factors which determine developmental plasticity of vegetative cells, and especially their embryogenic transition (Costa and Shaw 2006). Among the various factors that influence the induction of somatic embryogenesis (SE), such as plant growth regulators and other media components, and 
physical culture conditions, or the donor genotype, the choice of explant type is considered to be crucial for the establishment of embryogenic culture, including in Arabidopsis (Gaj 2004). The embryogenic response is usually limited to specific tissues, strictly defined in age and developmental stage, and thus a selection of the proper explant type is a prerequisite for successful SE induction.

In many plants zygotic embryos provide explants with high SE potential, although their developmental stage allowing for embryogenic transition varies considerably between species (Elhiti and Stasolla 2011). Mature zygotic embryos (MZEs) are efficient in SE induction in some species (Prakash and Gurumurthi 2010; Chen et al. 2010; You et al. 2011; Pinto et al. 2011), mainly in cereals (Sharma et al. 2005); but immature zygotic embryos (IZEs) have been most frequently used to start embryogenic culture in plants of various taxonomic groups (Gaj 2004). Importantly, a strictly defined developmental stage of IZE determines high capacity for SE, and in most plants the competency of IZE for SE decreases with their age (Ogita et al. 1999; Wendt dos Santos et al. 2002; Rai et al. 2010; Kong et al. 2011). In woody species especially, a declining competence for SE is correlated with IZE age, along with the accumulation of seed storage reserves (SSR) (Keinonen-Mettala et al. 1996; Kärkönen 2000; Corredoira et al. 2002).

In contrast to these species, and much less frequently, the IZEs advanced in maturation with accumulated nutrient reserves display higher embryogenic capacity, as described in Brassica napus (Turgut et al. 1998) and Panax ginseang (Choi et al. 1998). Similarly, in Feijoa sellowiana efficient SE induction can be achieved only in the culture of cotyledons, which have already accumulated storage proteins and lipids (Canhoto and Cruz 1996). In Arabidopsis, a model species in plant genomics, the highest competency for SE induction is provided by IZEs at the late cotyledon stage (Gaj 2001). This stage of seed development, spanning between 12 and 16th DAP (day after pollination), corresponds to the mid maturation phase of $\mathrm{ZE}$, and correlates with high synthesis and accumulation of proteins in cotyledons (Ruuska et al. 2002; Baud et al. 2008). The culture of IZEs at this stage results in rapid and efficient development of somatic embryos, mostly via the direct pathway induced in cotyledons (Kurczynska et al. 2007). On the contrary, IZEs of Arabidopsis at early stages of development (globular to torpedo) display drastically lower competency for SE, and abundant callus formation precedes somatic embryo development (Gaj 2001). The most distinct difference between poorly embryogenic IZEs, at the globular-torpedo stage, and highly embryogenic IZEs of late cotyledon stage, is the synthesis and accumulation of storage materials in the cotyledons (Mansfield and Briarty 1992).
There are also other observations suggesting a positive correlation between the accumulation of seed storage proteins (SSPs) in tissues and the competence for SE in Arabidopsis. Accordingly, beside IZEs, the only postembryonic vegetative tissues in Arabidopsis able to develop somatic embryos were found in some genotypes which ectopically accumulate the SSRs, due to mutation or induced over-expression of some specific embryogenesisrelated regulatory genes. The pickle mutant shows spontaneous production of somatic embryos in seedling roots which display ectopic expression of SSPs genes (Ogas et al. 1997). The spontaneous or enhanced somatic embryo formation on seedling aerial parts, accompanied by SSR ectopic expression, was found in transgenic lines overexpressing transcription factors involved in SE induction, including: LEAFY COTYLEDON2 (Stone et al. 2001), BABY BOOM (Boutilier et al. 2002), AGL15 (Harding et al. 2003), as well as MYB118 and MYB115 (Wang et al. 2009). Conversely, the abi3, and lec mutants, with severely reduced SSPs accumulation in seeds (Fujiwara et al. 2002), were found to be significantly defective in SE response (Gaj et al. 2005, 2006).

All these observations lead to the hypothesis that the seed maturation process, mainly the SSP accumulation, provides a suitable or even indispensable environment for the initiation of SE in Arabidopsis (Stone et al. 2008). However, the nature and the mechanisms involved in the relation between embryogenic competency of somatic tissue and SSRs, remain to be revealed.

In Arabidopsis, as in other crucifers, synthesis of large amounts of storage reserves, including proteins and lipids, is related with seed development. These compounds are accumulated in the protein storage vacuoles (PSVs) and oil bodies (oleosomes), respectively, and each of these structures can constitute 30-40\% of MZE dry weight (North et al. 2010). In a post embryonic growth the SSPs and triacylglycerols (TAGs) stored in oleosomes are used as a reservoir of nutrients, and a source of energy during germination and plantlet development, before the autotrophic mode of feeding is switched on.

The main proteins stored in PSVs of Arabidopsis and other crucifer seeds are $12 \mathrm{~S}$ globulins (cruciferins). Globulins constitute a large fraction of dicotyledon, monocotyledon and gymnosperm SSPs, and belong to a large protein superfamily called cupins, which include a diverse array of prokaryotic as well as eukaryotic proteins that play a variety of different roles (Dunwell et al. 2000; Wan et al. 2007). Many of the cupin functions are dependent on enzymatic activity, but SSPs have lost this feature (Dunwell et al. 2000). The Arabidopsis Col-0 genome contains four cruciferin loci: At1g03880 (CRB), At1g03890 (CRU2), At4g28520 (CRC) and At5g44120 (CRA1), with the latter two contributing most to the cruciferin seed content (Wan et al. 2007; Baud 
et al. 2008). Oleosomes are spherical structures of $0.2-2.0 \mu \mathrm{m}$ in diameter, and they consist of a TAG core surrounded by phospholipid monolayer, which in turn is encapsulated by unique proteins called oleosins. Up to $50 \%$ of the oleosome surface is built up of proteins, mostly the plant specific oleosins, but also caleosins and steroleosin (Frandsen et al. 2001; Lin et al. 2002; North et al. 2010). Oleosins are known to prevent the coalescence of oil bodies, and thus help to maintain the small size of the oleosomes which stabilizes oil bodies and supports efficient oil metabolism during germination (Frandsen et al. 2001). Moreover, the proteins embedded in the lipid monolayer of oil bodies, including oleosins, play critical roles during degradation of storage lipids after germination (Baud and Lepiniec 2010). In the Arabidopsis genome 16 genes encode oleosins specific to seeds, microspores and tapetum (Kim et al. 2002). Among the seed-specific oleosins there are four proteins: OLEO1 (At4g25140), OLEO2 (At5g40420), OLEO3 (At5g51210) and OLEO4 (At3g27660). The most abundant is OLEO1, which constitutes $65 \%$ of Arabidopsis oleosome-associated proteins, and two others (OLEO2 and OLEO4) which contribute up to $30 \%$ of the oil-bodies proteome (Siloto et al. 2006).

The goal of the presented study was to gain insights into the relation between expression of genes encoding SSRs and tissue embryogenic potential. Two genes encoding CRUCIFERIN1 (At5g44120), and OLEOSIN4 (At3g27660) were selected for the analysis, due to their high expression level in embryogenic culture indicated in cDNA RDA (representational difference) analysis (MG and MDG, data not published). The $S S R$ gene expression patterns in vitro in relation to auxin treatment were analyzed, and genotypes of different embryogenic potential were evaluated. Moreover, the cral and oleo4 mutants were evaluated in respect to their in vitro culture capacity and stress response. The involvement of SSR genes in the improvement of embryogenic potential of explant tissue is discussed in the context of stress responses of in vitro cultured cells.

\section{Materials and methods}

Plant material and growth conditions

Several genotypes of Arabidopsis thaliana (L.) Heynh. with different capacities for SE were used. The wild type Col-0 ecotype that shows a high capacity in standard in vitro culture conditions (Gaj 2001) and the mutants impaired in SE were analyzed, including axr4-1, cbp20 (Gaj et al. 2006), lec2-1 (Gaj et al. 2005) and tan 1-2 (Baster et al. 2009). Additionally, cral-1 (SALK004699), cral-2 (SALK002668) and oleo4 (SALK011533) insertional mutants were used. The mutants carry T-DNA insertion in exons which almost always disturbs protein expression (Wang 2008). The cral and oleo4 mutants were evaluated in terms of their capacity for in vitro induced morphogenesis and stress responses.

The parental Col-0 ecotype, axr4-1, cral-1, cral-2 and oleo 4 mutants were purchased from NASC (The Nottingham Arabidopsis Stock Center). The tan1-2 and lec2 mutants were kindly provided by J. J. Harada (California University, Davies, USA), while the cbp20 mutant is part of the Max-Planck Institut für Züchtungsforschung Köln collection, and was kindly provided by Z. SzweykowskaKulinska, Institute of Molecular Biology and Biotechnology, AMU, Poznań.

Additionally, the Col-0 transgenic line (12/1/8) harboring a single copy of the 35S::LEC2-GR construct, and expressing a high and stable level of LEC2 transcript (Ledwoń and Gaj 2009), was also used in the experiments.

Plants used as the source of explants for SE culture and DNA extraction were grown in Jiffy-7 peat pots of $42 \mathrm{~mm}$ diameter (Jiffy), under controlled conditions: $22^{\circ} \mathrm{C}$, long day photoperiod $(16 \mathrm{~h} / 8 \mathrm{~h} \mathrm{L/D)}$ and light intensity of $100 \mu \mathrm{mol} \mathrm{m}{ }^{-2} \mathrm{~s}^{-1}$ in a 'walk-in' type growth chamber.

Explants and growth conditions for in vitro culture

IZEs and roots of seedlings were used as explants for in vitro culture. The IZE explants were isolated from the siliques of $8-12$ week old plants. The siliques were surface-sterilized for $20 \mathrm{~min}$ in a $20 \%$ solution of sodium hypochloride with three drops of Tween 20 per $100 \mathrm{ml}$, and rinsed three times in sterile water. Sterile siliques were opened with fine needles, and IZEs were excised under a dissecting microscope.

To produce root explants, seeds were surface-sterilized in a $20 \%$ solution of commercial bleach for $20 \mathrm{~min}$ and rinsed three times in sterile water. The seeds were germinated on $1 / 2$ MS medium with half concentration of Murashige and Skoog (1962) basal macro- and microelements, $10 \mathrm{~g} \mathrm{~L}^{-1}$ sucrose and $8 \mathrm{~g} \mathrm{~L}^{-1}$ agar. The roots were excised from 14 day old seedlings.

In vitro cultures were maintained in the controlled conditions of a growth chamber: $22^{\circ} \mathrm{C}$, long day photoperiod, light intensity $50 \mu \mathrm{mol} \mathrm{m} \mathrm{m}^{-2}$. All experiments were carried out in three replicates of at least 30 explants per each (10 explants/Petri dish).

Somatic embryogenesis

SE was induced in cultures of IZEs under in vitro conditions, according to the standard protocol for Arabidopsis (Gaj 2001). The IZEs isolated from the siliques were placed on SE induction E5 solid medium with B5 salts and 
vitamins (Gamborg et al. 1968), and supplemented with $5 \mu \mathrm{M}$ 2,4-D (2,4-dichlorophenoxyacetic acid), $20 \mathrm{~g} \mathrm{~L}^{-1}$ sucrose and $3,5 \mathrm{~g} \mathrm{~L}^{-1}$ Phytagel (Sigma). In addition to auxin medium, explant cultures were also established on E0 hormone-free medium.

The capacity for SE was evaluated by two parameters: SE efficiency (the percent of explants forming somatic embryos) and productivity (the average number of somatic embryos produced by a responding explant), calculated at 21 st day of culture.

\section{Shoot organogenesis}

The capacity for in vitro shoot organogenesis (ORG) was evaluated in cultures of two explant types: IZEs and seedling roots. The explants were placed for 7 days in a standard callus induction medium, CIM, with $2.2 \mu \mathrm{M}$ 2,4$\mathrm{D}$ and $0.2 \mu \mathrm{M}$ kinetin (Feldman and Marks 1986). Subsequently, the shoot induction media (SIM) of different hormonal composition were used, according to the explant type. SIM-R medium with $5 \mu \mathrm{M}$ 2iP (6-( $\alpha, \alpha$-dimethylallylamino)-purine) and $0.8 \mu \mathrm{M}$ IAA-indole-3-acetic acid (Feldman and Marks 1986), or SIM-C medium supplemented with $0.5 \mu \mathrm{M}$ naphthalene acetic acid (NAA) and $4.4 \mu \mathrm{M}$ benzyl adenine (BAP) were used to induce ORG in cultures of root and IZE explants, respectively. The capacity for ORG was evaluated in three-week old cultures on SIM. ORG efficiency was calculated as the percent of explants regenerating shoots. ORG productivity referred to the average number of shoots formed on the responding IZE or developed by $1 \mathrm{~cm}$ of root explant.

Induction of LEC2 protein activity in transgenic plants

To induce activity of the LEC2 protein a synthetic glucocorticoid, dexamethasone (water soluble DEX, Sigma), was added to the media at a concentration of $30 \mu \mathrm{M}$, as described by Ledwoń and Gaj (2009).

Analysis of stress responses in seed germination assay

Seeds were sterilized with chlorine gas in a dessicator jar and plated onto $1 / 4$ MS (Murashige and Skoog 1962) salts with $10 \mathrm{~g} \mathrm{~L}^{-1}$ sucrose and $8 \mathrm{~g} \mathrm{~L}^{-1}$ agar. The percentage of seed germination was scored on media with different concentrations of $\mathrm{NaCl}(0 ; 50 ; 150$ and $200 \mathrm{mM})$ and mannitol $(0 ; 100 ; 200$ and $300 \mathrm{mM})$. Plates were chilled at $4^{\circ} \mathrm{C}$ in the dark for 3 days and moved to $22^{\circ} \mathrm{C}$ with a $16 \mathrm{~h}$-light/8h-dark cycle with light intensity of $100 \mu \mathrm{mol} \mathrm{m} \mathrm{m}^{-2} \mathrm{~s}^{-1}$. Germination was defined by emergence of the radicle through the seed coat and the evaluation was carried at 4th day after stratification. In each experimental combination 80-120 seeds in three replications were evaluated.
RNA isolation and RT-qPCR analysis

Total RNA for RT-qPCR analysis was isolated with the RNAqueous kit (Ambion) at the selected time points of SE and ORG cultures $(0,1,3,5,10$ and 15 day), and during IZEdevelopment on E0 medium (0, 1, 3, 5, 10 day). The concentrations and purity of RNA were evaluated with a ND-1000 spectrophotometer (NanoDrop). RNAs were treated with RQ1 RNase-free DNase I (Promega), following the manufacturer's instructions. cDNA synthesis was carried out with the RevertAid $^{\mathrm{TM}}$ First Strand cDNA Synthesis Kit (Fermentas). Standard cDNA samples with sevenfold serial dilution were used for PCR efficiency calculations. Amplification curves were generated for all used primers pair. The relative expression level of the genes was determined with the LightCycler 2.0 system (Roche), and gene specific primers. The At4g27090 gene encoding ribosomal 60S L14 protein was used as the standard control (Thellin et al. 1999; Gaj et al. 2005; Yamagishi et al. 2005; Braybrook et al. 2006; Baster et al. 2009; Ledwoń and Gaj 2009), and the following primers were used for RTqPCR reactions of the analysed genes: OLEO4 (R)-5'GCCAAGATTCCCGTCACAGC-3'; OLEO4 (F)-5'-CGCG GCCCCTCCACTAAC-3'; CRAl (R)-5'-TGGTTCCTGTCC GTCGTTGT-3'; CRAl (F)-5'-TCGTGGCTAAGGGACGAGGT-3'; At4g27090 (R)-5'-CCTCGATCAAAGCCTTCT TCT-3'; At4g27090 (F)-5'-GTCGTTATCGTCGACGTTG TT- $3^{\prime}$.

RT-qPCR reactions contained the fluorescent dye SYBR Green (LightCycler FastStart DNA Master SYBR Green I-Roche), and the results were analyzed with the LightCycler 4 Software (Roche). In all analyzed tissue samples the control gene exhibited a constant expression pattern with $\mathrm{Cp}=18 \pm 1$. All experiments were conducted with at least 3 biological replicates, and the Real-time qPCR reactions were repeated twice.

\section{Identification of insertional mutants}

The seeds of cral-1, cral-2 and oleo 4 insertional mutants were purchased as part of the $\mathrm{T}_{3}$ segregating lines (Alonso et al. 2003). To identify homozygous mutants DNA was isolated from individual $\mathrm{T}_{3}$ plants using a modified microCTAB method (Doyle and Doyle 1987). PCR reactions containing two genes and one insert specific primer (http://signal.salk.edu/tdnaprimers.html) were then conducted. The size of amplified products indicated the homoor hemizygous status of the plants, in terms of the presence of the insert within the gene of interest.

Statistical analysis

The Kruskal-Wallis ANOVA test was employed for the analysis, followed by U Mann-Whitney test. The average 
value for three biological replicates with the standard deviation is presented.

\section{Results}

\section{Expression of CRAI and OLEO4}

\section{Callus versus embryogenic culture}

To answer the question whether the transcription of SSR genes is correlated with embryogenic tissue the explants at day 15 of culture on E5 medium, efficiently forming somatic embryos, and those occasionally producing only non-embryogenic callus (Fig. 1), were compared in terms of $C R A 1$ and OLEO4 transcription level. It was found that the expression level of CRAI and OLEO4 was significantly higher (up to 17 fold) in Col-0 culture efficiently forming somatic embryos than in callus developing from explants which failed in embryogenic induction (Fig. 2).

\section{Alternative morphogenic pathways induced in vitro}

IZEs of Col-0 treated with auxin, $5 \mu \mathrm{M} 2,4-\mathrm{D}$ in E5 medium, undergo efficient SE induction, while the use of auxin and cytokinin in CIM-SIM-C medium combination triggers effective shoot regeneration. In contrast, hormone free medium (E0) enables development of IZEs into seedlings. Real-time qPCR analysis indicated that CRAI and OLEO4 displayed a similar expression pattern in IZEs cultured under alternative hormonal treatment (Fig. 3). At the first day (1 day) of culture, regardless of medium applied, the transcription level of the both genes dropped significantly. Then, a gradual increase of CRAl and OLEO4 expression was noticed during seedling development on hormone-free medium. In contrast to E0 medium, explants induced in presence of auxin to induce SE or auxin combined with cytokinin to induce ORG displayed

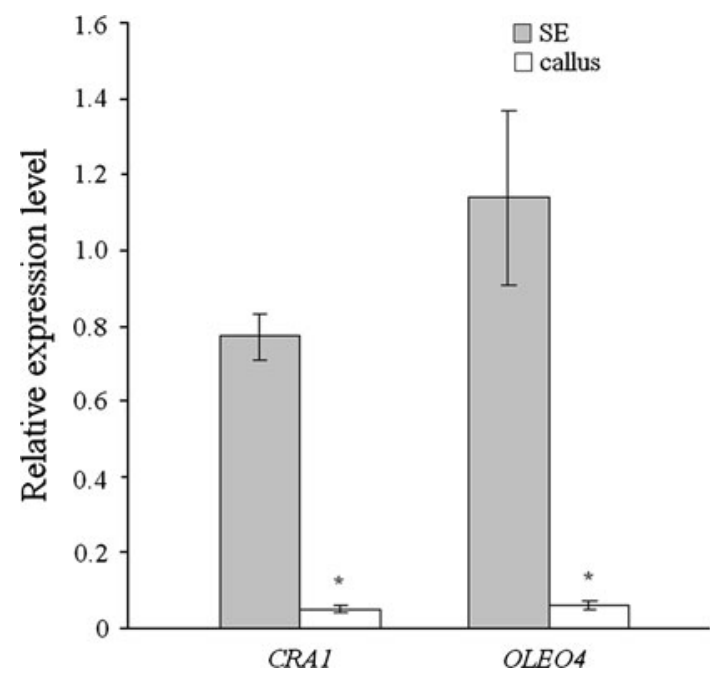

Fig. 2 CRA1 and OLEO4 expression level in 15 days old Col-0 cultures of different embryogenic capacity: highly embryogenic culture (SE) and non-embryogenic callus. *Values significantly different from those observed in SE culture $(P<0.05)$

relatively constant and significantly lower than in freshly isolated explants, transcription level. The results indicated that $C R A 1$ and $O L E O 4$ expression pattern is not specific for embryogenic culture, and instead of auxin-stimulation assumed for SE-specific genes down-regulation of transcription was observed.

\section{LEC2 overexpression}

The expression level of CRAI and OLEO4 was also investigated in E5 cultures derived from 35S::LEC2-GR; Col-0 explants to reveal the relation between $L E C 2$ expression and activity of $S S R$ genes under in vitro conditions. The results indicated that the transcription level of CRAI and OLEO4 dropped in SE culture, irrespective of $L E C 2$ expression induced by inclusion of DEX into E5 medium (Fig. 4).
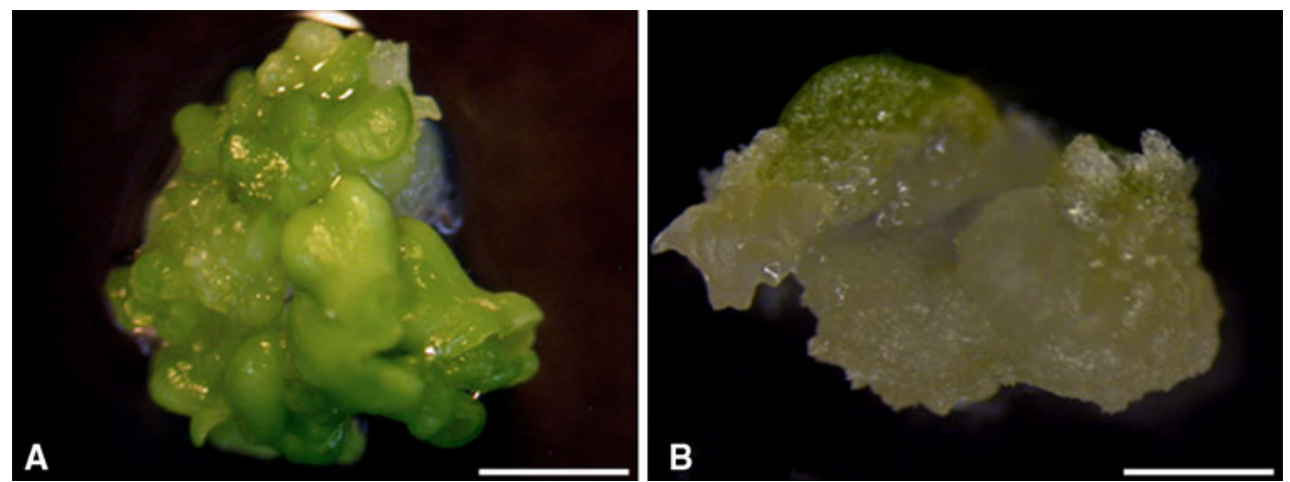

Fig. 1 IZE-derived on E5 medium Col-0 cultures at 15 days of different embryogenic capacity a highly embryogenic culture producing numerous somatic embryos; b non-embryogenic callus. Scale bars $=0.4 \mathrm{~cm}$ 

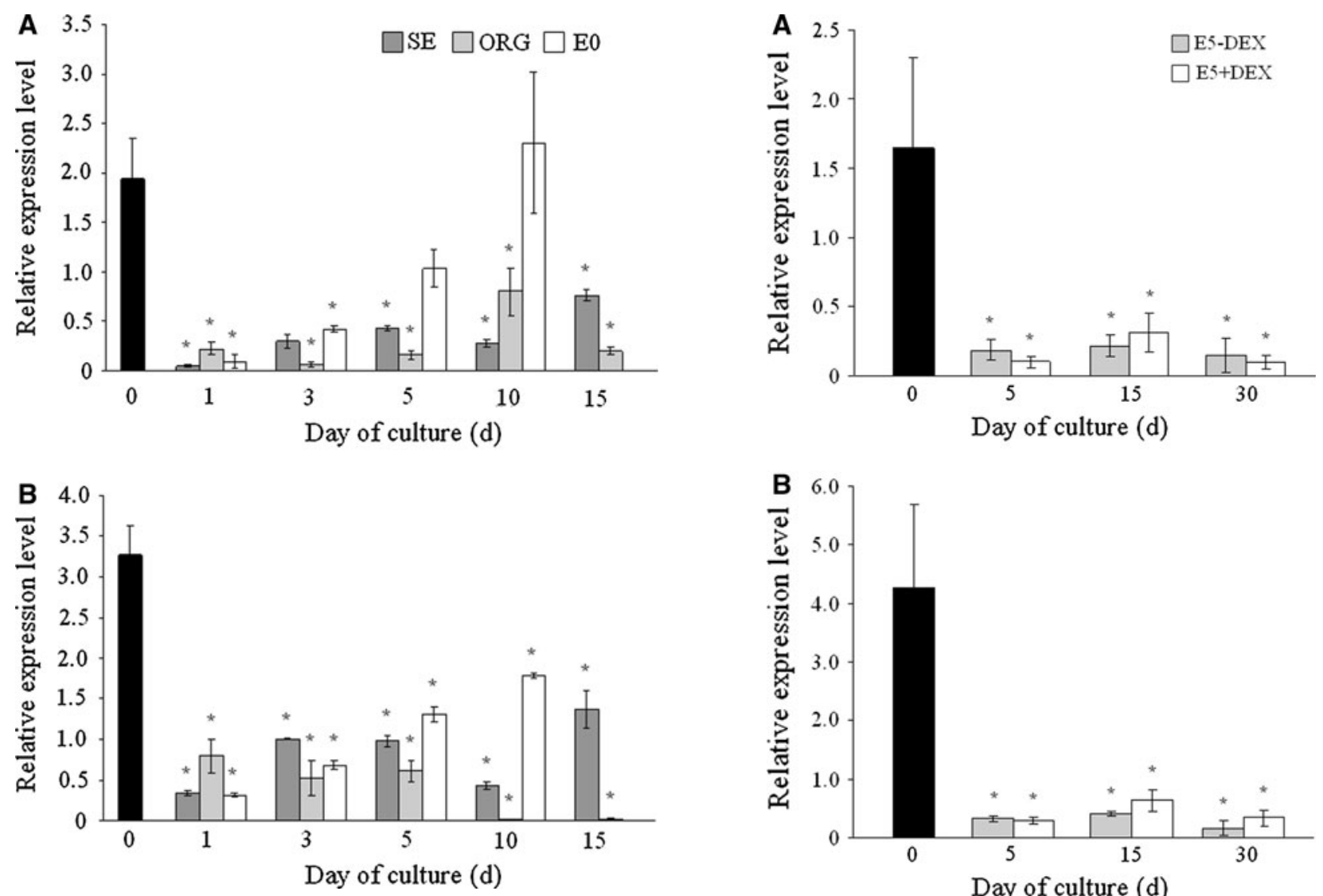

Fig. 3 Expression level of CRA1 (a) and OLEO4 (b) genes during IZE-derived cultures of the Col-0 induced towards somatic embryo formation (SE), shoot regeneration (ORG) or seedling development (E0). *Values significantly different from those observed at 0 day $(P<0.05)$

\section{Mutants impaired in SE}

We found it interesting to compare the transcription level of the CRAI and OLEO4 genes in IZE cultures of highly embryogenic Col-0 genotype and severely impaired in SE mutants, axr4-1, $\operatorname{cbp} 20, \operatorname{lec} 2$ and tan 1-2. It was observed that transcript level of both genes in freshly isolated explants (0 day) of the SE-impaired mutants was not reduced in comparison to highly embryogenic Col-0 (control) explants, but was found even significantly higher for OLEO4 in IZEs of $c b p 20$ and tan 1-2 mutants (Table 1). During E5 culture, the expression pattern of CRAl and OLEO4 in mutant-derived cultures was similar to that displayed by Col-0. Accordingly, significant down-regulation of their activity was observed during the culture, however the decrease in CRAI and OLEO4 transcription was more drastic in SE-impaired mutant cultures than in highly embryogenic control culture. Especially, expression of CRAI and OLEO4 was dramatically inhibited in culture of tanl-2 mutant.

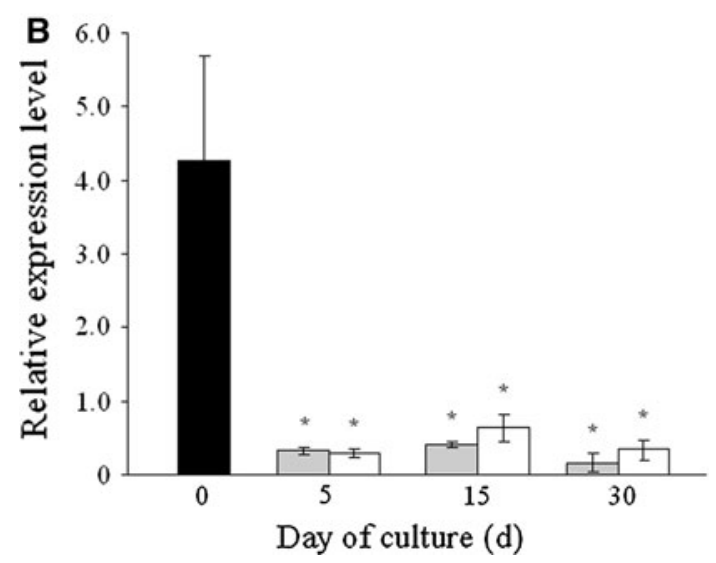

Fig. 4 Expression level of CRA1 (a) and OLEO4 (b) genes in IZE cultures of 35S::LEC2-GR, Col-0 induced on E5 medium in respect to DEX treatment. *Values significantly different from those observed at 0 day $(P<0.05)$

In vitro morphogenic capacity of cral and oleo 4 mutants

In order to further investigate the relationship between genes encoding SSR, and embryogenic response of somatic tissue, the morphogenic potential of lines with mutations in OLEO4 and CRAI genes were assessed. Two insertional mutant lines for the CRAl gene (cral-1, cral-2), and one line (oleo4) for OLEO4, were studied under in vitro culture. The phenotypes of the mutants in planta were carefully inspected and no distinct morphological changes were noticed. Morphology of zygotic embryos, seedlings and plants including growth rate, flowering time and fertility were found similar to Col-0 control plants. In contrast, both mutations were found to significantly impair embryogenic response of the IZE explants, and a significantly reduced frequency (over 50\%) of SE-responding explants was noticed in the mutant cultures (Fig. 5a). Additional to the deleterious effect on SE efficiency, mutations in CRAI gene did not significantly reduce embryo number (Fig. 5b). 
Table 1 Expression level of OLEO4 and CRA1 genes during in vitro culture on E5 medium of SE-impaired mutants (axr4-1, cbp20, lec2, tan1-2), compared with the Col-0 genotype.

* Values significantly different from those observed in Col-0 culture at the same stage of culture $(P<0.05)$

\begin{tabular}{|c|c|c|c|c|c|}
\hline & 0 day & 1 day & 5 days & 10 days & 15 days \\
\hline \multicolumn{6}{|c|}{ OLEO4 } \\
\hline Col-0 & $2.07 \pm 0.86$ & $0.32 \pm 0.03$ & $0.92 \pm 0.1$ & $0.47 \pm 0.07$ & $0.87 \pm 0.29$ \\
\hline axr4-1 & $2.05 \pm 0.75$ & $0.24 \pm 0.1$ & $0.53 \pm 0.05 *$ & $0.23 \pm 0.04 *$ & $0.34 \pm 0.07^{*}$ \\
\hline $\operatorname{cbp} 20$ & $3.53 \pm 1.97 *$ & $0.22 \pm 0.01 *$ & $0.22 \pm 0.1 *$ & $0.04 \pm 0.02 *$ & $0.05 \pm 0.01 *$ \\
\hline $\operatorname{lec} 2$ & $2.47 \pm 0.0$ & $0.8 \pm 0.32 *$ & $0.34 \pm 0.06^{*}$ & $0.06 \pm 0.02 *$ & $0.09 \pm 0.02 *$ \\
\hline $\tan$ & $5.87 \pm 2.33^{*}$ & $0.35 \pm 0.1$ & $0.09 \pm 0.03 *$ & $0.0012 \pm 0.0001^{*}$ & $0.002 \pm 0.003 *$ \\
\hline \multicolumn{6}{|l|}{ CRA1 } \\
\hline Col-0 & $1.48 \pm 0.85$ & $0.04 \pm 0.02$ & $0.39 \pm 0.08$ & $0.25 \pm 0.06$ & $0.56 \pm 0.36$ \\
\hline axr4-1 & $0.59 \pm 0.42$ & $0.04 \pm 0.04$ & $0.35 \pm 0.07$ & $0.23 \pm 0.1$ & $0.26 \pm 0.08$ \\
\hline $\operatorname{cbp} 20$ & $3.87 \pm 2.03$ & $0.05 \pm 0.03$ & $0.14 \pm 0.03 *$ & $0.03 \pm 0.02 *$ & $0.03 \pm 0.01 *$ \\
\hline $\operatorname{lec} 2$ & $1.86 \pm 0.0$ & $0.43 \pm 0.36^{*}$ & $0.27 \pm 0.03$ & $0.04 \pm 0.02 *$ & $0.06 \pm 0.03^{*}$ \\
\hline $\tan$ & $2.94 \pm 1.1$ & $0.29 \pm 0.07^{*}$ & $0.09 \pm 0.07 *$ & $0.00003 \pm 0.0002^{*}$ & $0.00004 \pm 0.000039^{*}$ \\
\hline
\end{tabular}
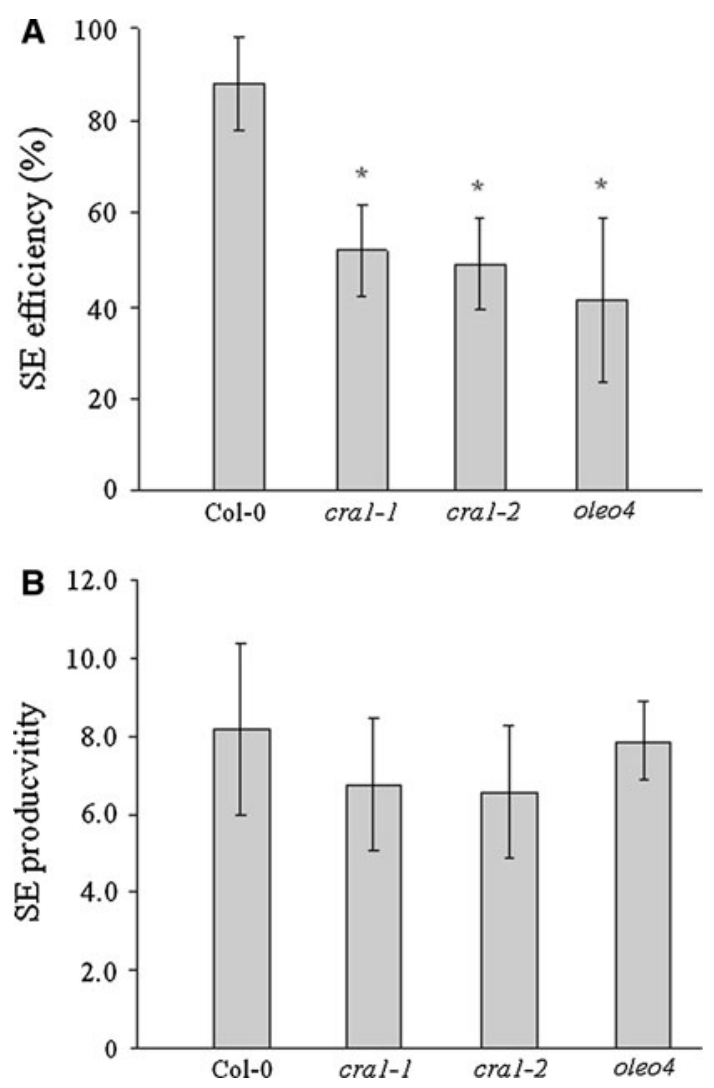

Fig. 5 Capacity for SE in cultures of cral (cral-1 and cral-2) and oleo 4 mutants and their parental Col-0 genotype. a SE efficiency; b SE productivity. *Values significantly different from those observed for Col-0 $(P<0.05)$

To verify whether the reduction in morphogenetic potential of cral and oleo 4 mutants is specific for SE induction, the capacity of the insertional mutants for in vitro ORG was also evaluated. Two explant types which require different hormone treatment to induce shoot regeneration were used-cotyledons of IZEs and seedling roots. In contrast to SE inductive conditions, the mutant
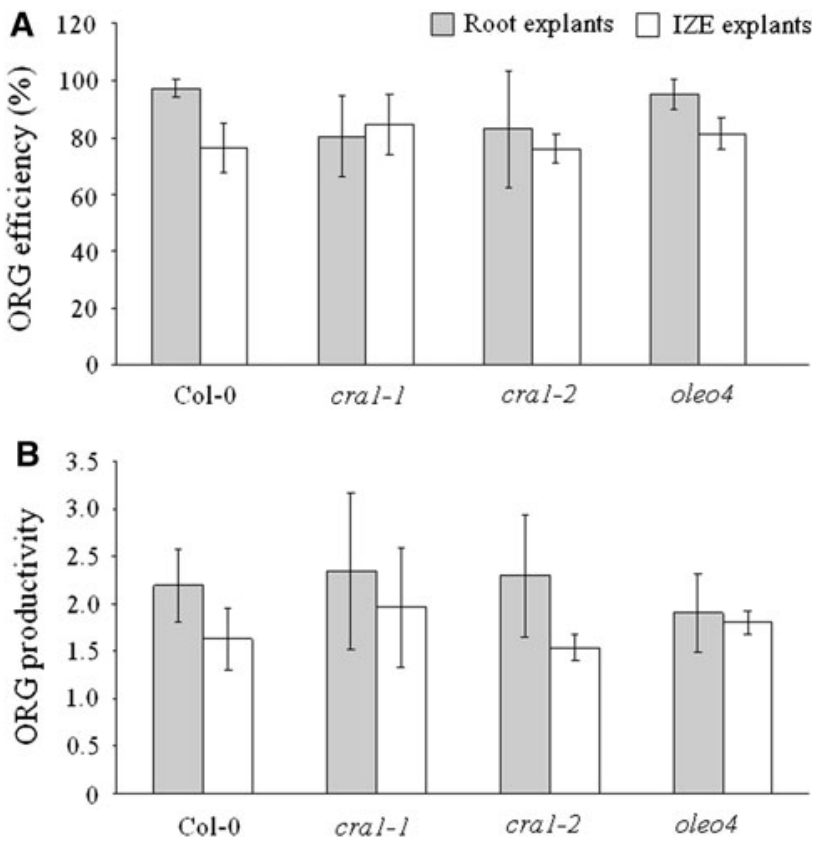

Fig. 6 High efficiency (a) and productivity (b) for shoot ORG in 21 days root and IZE-derived cultures of Col-0 genotype and cral-1; cral-2 and oleo 4 mutants

explants subjected to shoot induction displayed an efficiency similar to Col-0 culture capacity for shoot regeneration, in terms of efficiency (Fig. 6a) and productivity (Fig. 6b) of organogenesis. This observation suggests that mutations in OLEO4 and CRAl genes specifically impair tissue capacity for SE.

cral and oleo 4 mutant responses to stress treatment

To reveal mechanism of SE-impaired response observed in culture of the cral and oleo 4 mutants we evaluated sensitivity of these mutants to stress factors. To this end, the frequency of germination in the mutant and control seeds 

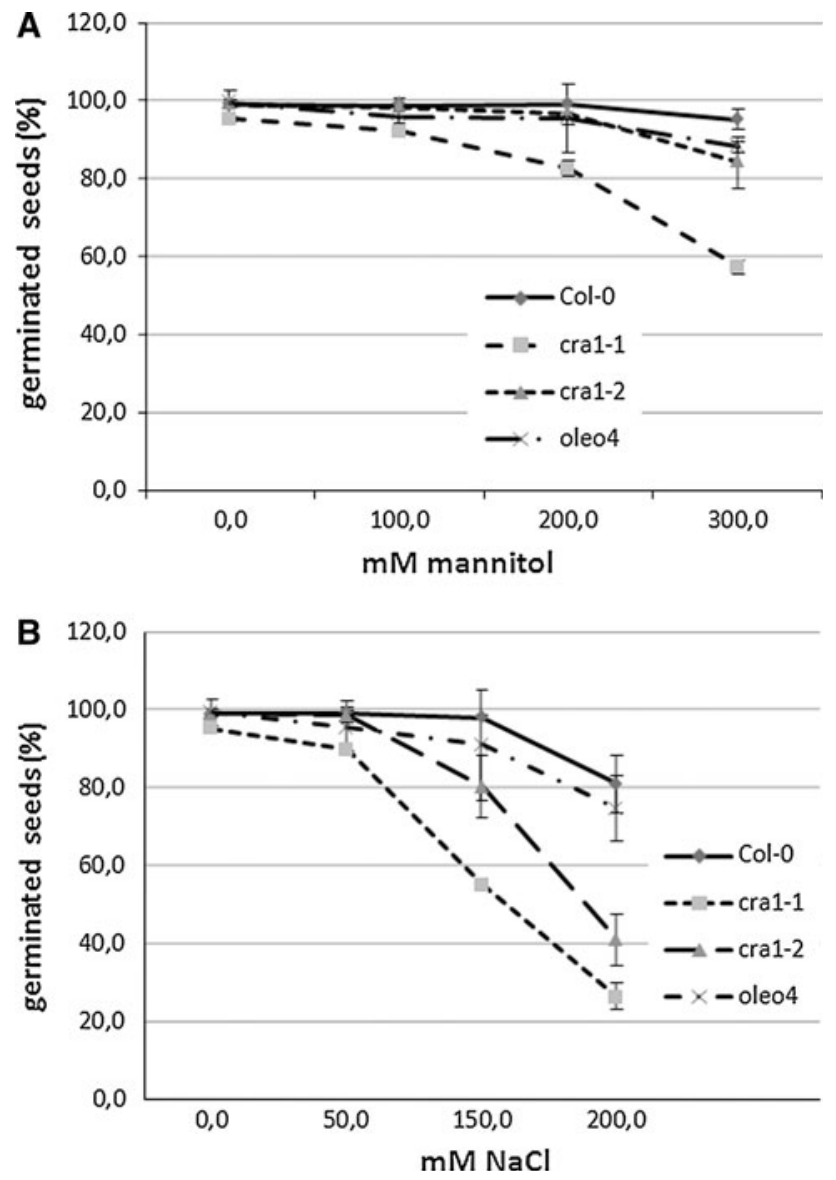

Fig. 7 Seed germination frequency of cral-1, cral-2 and oleo 4 mutants under stress induced with mannitol (a) and $\mathrm{NaCl}(\mathbf{b})$

were evaluated on media supplemented with different concentrations of $\mathrm{NaCl}$ and mannitol (Fig. 7). It was noticed that both $\mathrm{cral}$ mutants displayed decreased tolerance to $\mathrm{NaCl}$. On average, $50-75 \%$ less of $\mathrm{cral}-1$ and cral-2 than Col-0 seeds germinated on medium with $200 \mathrm{mM} \mathrm{NaCl}$. Beside $\mathrm{NaCl}$, cral-1 seeds were also found more sensitive to mannitol, and its inclusion into the medium at a concentration of $300 \mathrm{mM}$ of inhibited germination of over $40 \%$ of mutant seeds. The inhibitory effect of $\mathrm{NaCl}$ and mannitol on seed germination of other mutants tested were also noticed, however it was less pronounced.

\section{Discussion}

In Arabidopsis, it was proposed that the cellular environment conferring cell competence to switching on the embryogenic program of development in somatic cells is similar to that of the maturation phase zygotic embryos (Stone et al. 2008; Braybrook and Harada 2008). As the most distinct phenotype of ZE maturation phase is the accumulation of storage materials, the question remains as to whether these compounds are related with the determination of embryogenic potential in Arabidopsis.

Hence, in this study the genes encoding representatives of the major storage compounds of Arabidopsis seeds, cruciferin and oleosin were studied, in terms of their transcription profiles in in vitro cultured tissue. It was indicated that although $S S R$ genes display significantly higher activity in cultures efficiently producing somatic embryos than in callus, their expression was found to be not stimulated by auxin treatment, the key factor in SE induction. Moreover, the expression pattern of CRA1 and OLEO4 was revealed to be nonspecific to embryogenic culture. These observation rendered the hypothesis of direct involvement of SSR genes in SE induction rather unlikely. Thus, it can be assumed that transcription of SSRS in cultured somatic tissue may result from the activity of their regulatory genes, including those of essential function in SE induction. Accordingly, LEC2, a master regulator of ZE (Harada 2001), which directly controls $12 \mathrm{~S}$ storage protein genes, including CRAl gene (Braybrook et al. 2006; Stone et al. 2008), was shown to determine SE induction in IZE culture (Gaj et al. 2005; Ledwoń and Gaj 2009). Several observations show that during ZE expression the pattern of SSR did not directly follow $L E C 2$ expression. In seed development the highest expression of $L E C 2$ was detected from the early to the mid stages of ZE (Stone et al. 2001; Santos-Mendoza et al. 2008; Stone et al. 2008), and preceded the highest accumulation of SSR transcripts observed in mature seeds (Ruuska et al. 2002). Our observations on SE indicated that, in parallel to ZE, up-regulation of $L E C 2$ activity is characteristic for the early phases of embryogenic culture (Ledwoń and Gaj 2009), while increased $S S R$ expression was detected in advanced embryogenic cultures producing cotyledon-stage somatic embryos (present results).

Moreover, it was found that an elevated LEC2 expression induced in $35 \mathrm{~S}::$ LEC2 transgenic explants did not stimulate $C R A 1$ expression in embryogenic culture. Similarly, up-regulation of $C R A I$ and $O L E O$ was not observed in seeds of transgenic lines, in contrast to stimulation of these genes in postembryonic organs overexpressing $L E C 2$ (Stone et al. 2008). These observations suggest that some similarities exist in relations between $S S R$ and $L E C 2$ in terms of their expression pattern during ZE and SE.

In addition, the analysis of SE-defective mutants revealed that high activity of CRAI and OLEO4 found in some of them is not sufficient to define SE-promoting environment in explant tissue.

Collectively, the results on expression patterns of SSR genes analyzed in relation to various tissue culture conditions and genotypes did not implicate a direct or specific role of these genes in SE induction, but rather illustrate some similarities to their activity during ZE. 
However, the observations that cral and oleo 4 mutations significantly impaired SE induction in IZE-derived cultures suggest that SSR genes may contribute to embryogenic induction. Possibly, the activity of $C R A l$ and OLEO4 genes can improve the SE-conducive cellular environment, and support the perception of an embryogenic signal by explant tissue resulting in the onset of embryogenic development. A possible role of SSR in SE induction should be considered in the context of a stressrelated concept of SE induction. An immense body of recent data strongly supports the idea that mechanisms governing cell reprogramming and transcriptome alteration necessary for somatic cells to acquire an embryogenic state imitate stress-related responses (Fehér et al. 2003; Zavattieri et al. 2010; Karami and Saidi 2010; Grafi et al. 2011). In support of the postulated positive relation between $S S R$ responsiveness to stress and tissue competence for SE, storage product genes were indicated among those induced in response to several abiotic and biotic stresses, to which various plants were subjected (Gong et al. 2001; Rossel et al. 2002; Shewry 2003; Vooková et al. 2006; Zhang et al. 2009; Sobhanian et al. 2010; Sharma et al. 2010), including Arabidopsis (Berger et al. 2002; Baud et al. 2008). Relevantly to the genes analysed in the present work, water stress induced the transcription of cruciferin genes in rapeseed (Moons et al. 1997), and oleosins were documented to be involved in plant response to abiotic stress exerted by freezing (Shimada et al. 2008).

Thus, it can be speculated that impaired stress-related mechanisms are responsible for decreased embryogenic responses presented by the mutants defective in cruciferin and oleosin expression. In support for this assumption, we observed reduced tolerance to high salinity and osmotic pressure in cral mutants. Interestingly, these stress factors were reported to enhance SE-capacity of Arabidopsis seedling tissue treated with auxin (Ikeda-Iwai et al. 2003). Further support to the possible link between SSR genes, stress tolerance and capacity for SE is provided by observation that in conifers, germin-like proteins recognized as stress-related proteins, were suggested to play a central role in somatic embryo formation via the regulation of cell wall remodeling (Mathieu et al. 2003).

Postulation on the positive influence of SSR genes on enhanced embryogenic capacity of cultured tissue, possibly via improvement of cell response to stress imposed in vitro, is also in agreement with the recent view on seed maturation phenomenon. It is postulated that the biological processes found in $\mathrm{ZE}$, and leading to mature seeds, may not contribute to the function of the seed per se (Angelovici et al. 2010). In this perspective, it is speculated that the maturating seeds, which accumulate vast number of various proteins and transcripts, acquire higher developmental plasticity. Some recent observations suggest that apart from providing energy to the post-germinative seedling (Penfield et al. 2006), SSR may have unexpectedly new, not yet defined functions during post-embryonic development of plants. Accordingly, the transcription of caleosin, a storage protein believed to be seed specific, was observed transiently in root tips of Arabidopsis (Næsted et al. 2000), while oleosin transcripts were detected at a relatively high level in young root meristems of Brassica napus (Murphy et al. 2001).

Based on our results, indicating that the defective embryogenic responses of $\mathrm{cral}$ and oleo 4 mutants is coupled with their impaired tolerance to stress factors, it is conceivable that high activity of SSR genes in IZEs of Arabidopsis indirectly increases embryogenic response of somatic tissue, through providing a better endogenous environment to respond under stress conditions. Mechanisms which relate high activity of $S S R$ and improved stress responsiveness of somatic tissue remain to be elucidated.

Open Access This article is distributed under the terms of the Creative Commons Attribution Noncommercial License which permits any noncommercial use, distribution, and reproduction in any medium, provided the original author(s) and source are credited.

\section{References}

Alonso JM, Stepanova AN, Leisse TJ, Kim CJ, Chen H, Shinn P, Stevenson DK, Zimmerman J, Barajas P, Cheuk R, Gadrinab C, Heller C, Jeske A, Koesema E, Meyers CC, Parker H, Prednis L, Ansari Y, Choy N, Deen H, Geralt M, Hazari N, Hom E, Karnes M, Aguilar-Henonin L, Schmid M, Weigel DL, Carter DE, Marchand T, Risseeuw E, Brogden D, Zeko A, Crosby W, Berry CC, Ecker JR (2003) Genome-wide insertional mutagenesis of Arabidopsis thaliana. Science 301:653-657

Angelovici R, Galili G, Fernie AR, Fait A (2010) Seed desiccation: a bridge between maturation and germination. Trends Plant Sci 4:211-218

Baster P, Ledwoń A, Gliwicka M, Trojanowska A, Gaj MD (2009) Arabidopsis tanmeilemb2757 embryo mutant is defective for in vitro plant morphogenesis. Plant Cell Tissue Organ Cult 99: 305-312

Baud S, Lepiniec L (2010) Physiological and developmental regulation of seed oil production. Prog Lipid Res 49:235-249

Baud S, Dubreucq B, Miquel M, Rochat C, Lepiniec L (2008) Storage reserve accumulation in Arabidopsis: metabolic and developmental control of seed filling. In: The Arabidopsis book. American Society of Plant Biologists, Rockville. doi:10.1199/tab.0113, http://www.aspb.org/publications/arabidopsis/

Berger S, Mitchell-Olds T, Stotz HU (2002) Local and differential control of vegetative storage protein expression in response to herbivore damage in Arabidopsis thaliana. Physiol Plant 114:85-91

Boutilier K, Offringa R, Sharma VK, Kieft H, Ouellet T, Zhang L, Hattori J, Liu CM, van Lammeren AAM, Miki BLA, Custers JBM, van Lookeren Compagne MM (2002) Ectopic expression of $B A B Y B O O M$ triggers a conversion from vegetative to embryonic growth. Plant Cell 14:1737-1749

Braybrook SA, Harada JJ (2008) LECs go crazy in embryo development. Trends Plant Sci 13:624-630 
Braybrook SA, Stone SL, Park S, Bui AQ, Le BH, Fischer RL, Goldberg RB, Harada JJ (2006) Genes directly regulated by LEAFY COTYLEDON2 provide insight into the control of embryo maturation and somatic embryogenesis. Proc Natl Acad Sci USA 103:3468-3473

Canhoto JM, Cruz GS (1996) Histodifferentiation of somatic embryos in cotyledons of pineapple guava (Feijoa sellowiana Berg). Protoplasma 191:34-45

Chen AH, Yang JL, Niu YD, Yang CP, Liu GF, Yu CY, Li CH (2010) High-frequency somatic embryogenesis from germinated zygotic embryos Schisandra chinensis and evaluation of the effects of medium strength, sucrose, GA3, and BA on somatic embryos development. Plant Cell Tissue Organ Cult 102:357-364

Choi YE, Yang DC, Park JC, Soh WY, Choi KT (1998) Regenerative ability of somatic single and multiple embryos from cotyledons of Korean ginseng on hormone-free medium. Plant Cell Rep 17:544-551

Corredoira E, Vieitez AM, Ballester A (2002) Somatic embryogenesis in elm. Ann Bot 89:637-644

Costa S, Shaw P (2006) 'Open minded' cells: how cells can change fate. Trends Cell Biol 17:101-106

Doyle JJ, Doyle JL (1987) A rapid DNA isolation procedure for small quantities of fresh leaf tissue. Phytochem Bull 19:11-15

Dunwell JM, Khuri S, Gane PJ (2000) Microbial relatives of the seed storage proteins of higher plants: conservation of structure and diversification of function during evolution of the cupin superfamily. Microbiol Mol Biol Rev 64:153-179

Elhiti M, Stasolla C (2011) The use of zygotic embryos as explants for in vitro propagation: an overview. In: Thorpe TA, Yeung EC (eds) Plant embryo culture: methods and protocols, methods in molecular biology. Humana Press, Totowa, pp 229-255

Fehér A, Pasternak TP, Dudits D (2003) Transition of somatic plant cells to an embryogenic state. Plant Cell Tissue Organ Cult 74:201-228

Feldman JH, Marks MD (1986) Rapid and efficient regeneration of plant of Arabidopsis thaliana. Plant Sci 47:63-69

Frandsen GI, Mundy J, Tzen JTC (2001) Oil bodies and their associated proteins, oleosin and caleosin. Physiol Plant 112:301-307

Fujiwara T, Nambara E, Yamagishi K, Goto DB, Naito S (2002) Storage proteins. In: Somerville CR, Meyerowitz EM (eds) The Arabidopsis book. American Society of Plant Biologists, Rockville. doi:10.1199/tab.0020, http://www.aspb.org/publications/ arabidopsis/

Gaj MD (2001) Direct somatic embryogenesis as a rapid and efficient system for in vitro regeneration of Arabidopsis thaliana. Plant Cell Tissue Organ Cult 64:39-46

Gaj MD (2004) Factors influencing somatic embryogenesis induction and plant regeneration with particular reference to Arabidopsis thaliana (L.) Heynh. Plant Growth Regul 43:27-47

Gaj MD, Zhang S, Harada JJ, Lemaux PG (2005) LEAFY COTYLE$D O N$ genes are essential for induction of somatic embryogenesis of Arabidopsis. Planta 222:977-988

Gaj MD, Trojanowska A, Ujczak A, Mędrek M, Kozioł A, Garbaciak B (2006) Hormone-response mutants of Arabidopsis thaliana (L.) Heynh. impaired in somatic embryogenesis. Plant Growth Regul 49:183-197

Gamborg OL, Miller RA, Ojima K (1968) Nutrient requirement of suspension culture of soybean root cells. Exp Cell Res 50: $151-158$

Gong Z, Koiwa H, Cushman MA, Ray A, Bufford D, Kore-eda S, Matsumoto TK, Zhu J, Cushman JC, Bressan RA, Hasegawa PM (2001) Genes that are uniquely stress regulated in salt overly sensitive (sos) mutants. Plant Physiol 126:363-375

Grafi G, Chalifa-Caspi V, Nagar T, Plaschkes I, Barak S, Ransbotyn V (2011) Plant response to press meets dedifferentiation. Planta 233:433-438
Harada JJ (2001) Role of Arabidopsis LEAFY COTYLEDON genes in seed development. J Plant Physiol 158:405-409

Harding EW, Tang W, Nichols KW, Fernandez DE, Perry SE (2003) Expression and maintenance of embryogenic potential is enhanced through constitutive expression of AGAMOUS-Like15. Plant Physiol 133:653-663

Ikeda-Iwai M, Umehara M, Satoh S, Kamada H (2003) Stress-induced somatic embryogenesis in vegetative tissues of Arabidopsis thaliana. Plant J 34:107-114

Karami O, Saidi A (2010) The molecular basis for stress-induced acquisition of somatic embryogenesis. Mol Biol Rep 37: 2493-2507

Kärkönen A (2000) Anatomical study of somatic and zygotic embryos of Tilia cordata. Plant Cell Tissue Organ Cult 61:205-214

Keinonen-Mettala K, Jalonen P, Eurola P, von Arnold S, von Weissenberg K (1996) Somatic embryogenesis of Pinus sylvestris. Scand J For Res 11:242-250

Kim HU, Hsieh K, Ratnayake C, Huang AHC (2002) A novel group of oleosins is present inside the pollen of Arabidopsis. J Biol Chem 277:22677-22684

Kong D-M, Preece JE, Shen H-L (2011) Somatic embryogenesis in immature cotyledons of Manchurian ash (Fraxinus mandshurica Rupr.) Plant Cell Tissue Organ Cult. doi:10.1007/s11240011-0062-0

Kurczynska EU, Gaj MD, Ujczak A, Mazur E (2007) Histological analysis of direct somatic embryogenesis in Arabidopsis thaliana (L.) Heynh. Planta 266:619-628

Ledwoń A, Gaj MD (2009) LEAFY COTYLEDON2 gene expression and auxin treatment in relation to embryogenic capacity of Arabidopsis somatic cells. Plant Cell Rep 28:1677-1688

Lin L-J, Tai SSK, Peng C-C, Tzen JTC (2002) Steroleosin, a sterolbinding dehydrogenase in seed oil bodies. Plant Physiol 128: $1200-1211$

Mansfield SG, Briarty LG (1992) Cotyledon cell development in Arabidopsis thaliana during reserve deposition. Can J Bot 70: 151-164

Mathieu M, Neutelings G, Hawkins S, Grenier E, David H (2003) Cloning of a pine germ-like protein (GLP) gene promoter and analysis of its activity in transgenic tobacco bright yellow 2 cells. Physiol Plant 117:425-434

Moons A, Prinsen E, Bauw G, Van Montagu M (1997) Antagonistic effects of abscisic acid and jasmonates on salt stress-inducible transcripts in rice roots. Plant Cell 9:2243-2259

Murashige T, Skoog F (1962) A revised medium for rapid growth and bioassays with tobacco tissue cultures. Physiol Plant 15:473-497

Murphy DJ, Hernández-Pinzón I, Patel K (2001) Role of lipid bodies and lipid-body proteins in seeds and other tissues. J Plant Physiol 158:471-478

Næsted H, Frandsen GI, Jauh G-Y, Hernandez-Pinzon I, Nielsen HB, Murphy DJ, Rogers JC, Mundy J (2000) Caleosins: $\mathrm{Ca}^{2+}$. binding proteins associated with lipid bodies. Plant Mol Biol 44:463-476

North H, Baud S, Debeaujon I, Dubos C, Dubreucq B, Grappin P, Jullien M, Lepiniec L, Marion-Poll A, Miquel M, Rajjou L, Routaboul J-M, Caboche M (2010) Arabidopsis seed secrets unravelled after a decade of genetic and omics-driven research. Plant J 61:971-981

Ogas J, Cheng JC, Sung ZR, Somerville C (1997) Cellular differentiation regulated by gibberellin in the Arabidopsis thaliana pickle mutant. Science 277:91-94

Ogita S, Ishikawa H, Kubo T, Sasamoto H (1999) Somatic embryogenesis from immature and mature zygotic embryos of Cryptomeria japonica I: embryogenic cell induction and its morphological characteristics. J Wood Sci 45:87-91

Penfield S, Li Y, Gilday AD, Graham S, Graham IA (2006) Arabidopsis ABA INSENSITIVE4 regulates lipid mobilization 
in the embryo and reveals repression of seed germination by the endosperm. Plant Cell 18:1887-1899

Pinto DLP, de Almeida AMR, Rêgo MM, da Silva ML, de Oliveira EJ, Otoni WC (2011) Somatic embryogenesis from mature zygotic embryos of commercial passionfruit (Passilora edulis Sims) genotypes. Plant Cell Tissue Organ Cult. doi:10.1007/ s11240-011-0003-y

Prakash MG, Gurumurthi K (2010) Effects of type of explant and age, plant growth regulators and medium strength on somatic embryogenesis and plant regeneration in Eucalyptus camaldulensis. Plant Cell Tissue Organ Cult 100:13-20

Rai MK, Asthana P, Jaiswal VS, Jaiswal U (2010) Biotechnological advances in guava (Psidium guajava L.): recent developments and prospects for further research. Trees 24:1-12

Rossel JB, Wilson IW, Pogson BJ (2002) Global changes in gene expression in response to high light in Arabidopsis. Plant Physiol 130:1109-1120

Ruuska SA, Girke T, Benning C, Ohlrogge JB (2002) Contrapuntal networks of gene expression during Arabidopsis seed filling. Plant Cell 14:1191-1206

Santos-Mendoza M, Dubreucq B, Baud S, Parcy F, Caboche M, Lepiniec L (2008) Deciphering gene regulatory networks that control seed development and maturation in Arabidopsis. Plant J 54:608-620

Sharma VK, Hansch R, Mendel RR, Schulze J (2005) Mature embryo axis-based high frequency somatic embryogenesis and plant regeneration from multiple cultivars of barley (Hordeum vulgare L.). J Exp Bot 56:1913-1922

Sharma S, Singh J, Munshi GD, Munshi SK (2010) Effects of biocontrol agents on lipid and protein composition of Indian mustard seeds from plants infected with Alternaria species. Arch Phytopathol Plant Prot 43:589-596

Shewry PR (2003) Tuber storage proteins. Ann Bot 91:755-769

Shimada TL, Shimada T, Takahashi H, Fukao Y, Hara-Nishimura I (2008) A novel role for oleosins in freezing tolerance of oilseeds in Arabidopsis thaliana. Plant J 55:798-809

Siloto RMP, Findlay K, Lopez-Villalobos A, Yeung EC, Nykiforuk CL, Moloney MM (2006) The accumulation of oleosins determines the size of seed oilbodies in Arabidopsis. Plant Cell 18:1961-1974

Sobhanian H, Razavizadeh R, Nanjo Y, Ehsanpour AA, Jazii FR, Motamed N, Komatsu S (2010) Proteome analysis of soybean leaves, hypocotyls and roots under salt stress. Proteome Sci 8:19

Stone SL, Kwong LW, Yee KM, Pelletier J, Lepiniec L, Fisher RL, Goldberger RB, Harada JJ (2001) LEAFY COTYLEDON2 encodes B3 domain transcription factor induces embryo development. Proc Natl Acad Sci USA 98:11806-11811

Stone SL, Braybrook SA, Paula SL, Kwong LW, Meuser J, Pelletier J, Hsieh T-F, Fischer RL, Goldberg RB, Harada JJ (2008) Arabidopsis LEAFY COTYLEDON2 induces maturation traits and auxin activity: implications for somatic embryogenesis. Proc Natl Acad Sci USA 105:3151-3156

Thellin O, Zorzi W, Lakaye B, De Borman B, Coumans B, Hennen G, Grisar T, Igout A, Heinen E (1999) Housekeeping genes as internal standards: use and limits. J Biotechnol 75:291-295

Turgut K, Barghchi M, Scott R (1998) Efficient shoot regeneration and somatic embryogenesis from immature cotyledons of Brassica napus L. Plant Breeding 117:503-504

Vooková B, Hřib J, Kormuták A, Adamec V (2006) Defense reactions of developing somatic embryos of Algerian fir (Abies numidica). For Pathol 36:215-224

Wan L, Ross ARS, Yang J, Hegedus DD, Kermode AR (2007) Phosphorylation of the $12 \mathrm{~S}$ globulin cruciferin in wild-type and abi1-1 mutant Arabidopsis thaliana (thale cress) seeds. Biochem J 404:247-256

Wang YH (2008) How effective is T-DNA insertional mutagenesis in Arabidopsis? J Biochem Tech 1:11-20

Wang X, Niu Q-W, Teng C, Li C, Mu J, Chua N-H, Zuo J (2009) Overexpression of PGA37/MYB118 and MYB115 promotes vegetative-to-embryonic transition in Arabidopsis. Cell Res 19:224-235

Wendt dos Santos AL, Silveira V, Steiner N, Vidor M, Guerra MP (2002) Somatic embryogenesis in parana pine (Araucaria angustifolia (Bert.) O. Kuntze). Braz Arch Biol Tech 45:97-106

Yamagishi K, Nagata N, Yee KM, Braybrook SA, Pelletier J, Fujioka S, Yoshida S, Fischer RL, Goldberg RB, Harada JJ (2005) TANMEI/EMB2757 encodes a WD repeat protein required for embryo development in Arabidopsis. Plant Physiol 139:163-173

You XL, Tan X, Dai JL, Li YH, Choi YE (2011) Large-scale somatic embryogenesis and regeneration of Panax notoginseng. Plant Cell Tissue Organ Cult. doi:10.1007/s11240-011-0030-8

Zavattieri MA, Frederico AM, Lima M, Sabino R, Arnholdt-Schmitt B (2010) Induction of somatic embryogenesis as an example of stress-related plant reactions. Electron J Biotech 13:1-9

Zhang J, Ma H, Chen S, Ji M, Perl A, Kovacs L, Chen S (2009) Stress response proteins' differential expression in embryogenic and non-embryogenic callus of Vitis vinifera L. cv. Cabernet Sauvignon-a proteomic approach. Plant Sci 177:103-113 